Noname manuscript No.

(will be inserted by the editor)

\title{
Finding alternatives to handicap theory
}

\author{
Kevin J.S. Zollman
}

the date of receipt and acceptance should be inserted later

\begin{abstract}
The Handicap Principle represents a central theory in the biological understanding of signaling. This paper presents a number of alternative theories to the Handicap Principle and argues that some of these theories may provide a better explanation for the evolution and stability of honest communication.
\end{abstract}

Keywords Handicap principle · Costly signaling . Game theory · ESS

\section{Introduction}

Although it was initially derided (Pomiankowski and Iwasa, 1998; Grose, 2011), Zahavi's Handicap Principle (Zahavi, 1975; Zahavi and Zahavi, 1997) has come to occupy a central position in the theory of animal communication. The focal problem is the apparent stability of honest communication between two organisms when their interests conflict in a way that should render honesty unstable. This situation can arise in communication between parents and offspring, communication between potential mates, communication between prey and predators, communication between competitors, and many other situations. The Handicap Principle posits a cost to communication that, in one way or

The author would like to thank Carl Bergstrom, Simon Huttegger, and Brian Skyrms for helpful comments on earlier drafts. This material is based upon work supported by the National Science Foundation under Grant No. EF 1038456. Any opinions, findings, and conclusions or recommendations expressed in this material are those of the authors and do not necessarily reflect the views of the National Science Foundation.

\section{KJS Zollman}

Department of Philosophy, Carnegie Mellon University

Pittsburgh, PA, USA

E-mail: kzollman@andrew.cmu.edu another, renders dishonest communication unprofitable and thus makes honest communication stable.

The Handicap Principle's rise to prominence was largely achieved through a number of mathematical models beginning with the work of Grafen (1990). While these mathematical developments have demonstrated that the principle is not inconsistent with biological theory (contrary to early analyses, see Davis and O'donald 1976; Smith 1976; Kirkpatrick 1986), they do not eliminate the possibility that other mechanisms may be at work. This paper provides an overview of the alternative theories available to explain the presence of signaling, especially when the interests of the communicating parties conflict.

\section{The Handicap Principle}

In species where the parent provides resources to its offspring, there is the possibility for parent-offspring conflict. Because a parent is equally related to all of its offspring, but the offspring is related to a higher degree to itself than its siblings, the parent might prefer to withhold a resource from an offspring that the offspring wants. This might occur because the parent would prefer to allocate the resource to another offspring immediately or because the parent would prefer to consume the resource which would increase its chances of producing more offspring at a later date (Trivers, 1974).

These conflicts can give rise to many interesting familial dynamics (see for example Bergstrom and Bergstrom 1999), of particular interest here is communication between the offspring and parent. The canonical example was suggested by Maynard Smith (1991) (for variations see Johnstone and Grafen 1992, 1993; Bergstrom and Lachmann 1997, 1998; Lachmann and Berg- 
strom 1998; Godfray and Johnstone 2000; Brilot and Johnstone 2003). Suppose that there is a child that is in one of two states, needy or healthy. The parent and the child both would like the parent to provide a resource to the child when it is needy, but when the child is healthy there is a case of parent-offspring conflict the child would like the resource but the parent would prefer to withhold it. If we suppose that the child knows his state but the parent does not, we have a situation which allows for the possibility of signaling.

Suppose that the child has at his disposal two signals, call them begging or not begging. If neither of these signals come at a cost, we would not expect honest signaling to persist for long. To see this suppose that initially only the needy child begged and the healthy child did not. The parent does best by transferring the resource when the child begs and withholding it when the child does not. However, given this is the parent's response, the child would do best by begging regardless of its state of need, since he would prefer the resource when he is healthy. Once the child switches to this strategy, the parent then would do best by ignoring the signal and either always transferring or never transferring - which depends on the probability with which the child is needy.

This situation is interesting because occasionally, but not always, there exists parental-offspring conflict. If the parent never wanted to transfer the resource there would be no interesting familial dynamics. Alternatively, if the child did not want the resource when he was healthy, then we would have a situation of "common interest." In such a situation the stability of signaling would not be surprising, although there remain questions regarding the initial evolution of signaling (Pawlowitsch, 2008; Hofbauer and Huttegger, 2008; Huttegger, 2007; Huttegger and Zollman, 2009; Huttegger et al, 2010).

What then might make this signaling situation stable? The central proposal of the Handicap Principle and of the attending mathematical models is signal cost. Suppose that begging entailed a cost for the child, a cost that was sufficiently high so that is does not pay to secure the resource if the child is healthy but is worth paying to secure the resource if the child was needy. This might arise if either the benefit of the resource is higher for the needy child than the healthy one or if the cost of begging iss lower for the needy child than the healthy one (or both).

For parent-offspring conflict the former case - that the resource benefits the child differentially depending on need - is regarded as the most plausible. However, analogous situations might arise in mate selection or predator-prey interaction, and here differential cost seems more plausible.

That signals come with a cost, and by paying this cost one organism might reliably signal information to another despite the presence of occasional conflict of interest, represents the central tenant of the Handicap Principle. It is fair to say that this theory represents a central pillar of contemporary biological thought surrounding animal communication (Grose, 2011; Maynard Smith and Harper, 2003; Searcy and Nowicki, 2005).

\section{Problems with the Handicap Principle}

Despite its ubiquity, there has been a growing dissatisfaction with the Handicap Principle among both experimental and theoretical biologists in recent years. These concerns come both from empirical and theoretical developments that suggest the Handicap Principle may not be the primary explanation for the stability of signaling systems when interests occasionally conflict.

\subsection{Empirical concerns}

Because of its clear predictions about the presence of signal cost, the Handicap Principle has been subject to a number of empirical tests. Most widely studied has been begging behavior of birds. In this case, a number of well known behaviors are viewed as a signal of need to the parent. The cost is posited to come from either energetic costs in begging or increased predation risks which result from attracting predators to the nests.

A number of studies have been conducted, but these have tended to show that begging behavior has a relatively low cost. There do not seem to be either high metabolic costs (Bachmann and Champbell, 1998; McCarty, 1996) or high predation risk to birds from begging (Haskell 1994, but see Leech and Leonard 1997 for a study that finds high cost). This calls into question the Handicap Principle explanation which requires that signal cost be relatively large compared to the benefit from the resource that is being transferred.

Similar concerns have arisen in other context like signaling between mates (Borgia, 1993; Chappell et al, 1995), predator-prey signaling (Caro et al, 1995), and signaling between competitors (Silk et al, 2000) regarding the presence of signal costs. These empirical concerns have raised the possibility that in many species the explanation for honest communication lies outside of handicap theory. 


\subsection{Theoretical concerns}

While there is no mathematical concern with the original proofs that demonstrate the plausibility of the Handicap Principle, there have been several discoveries in these and other richer models that suggest previously overlooked difficulties for the explanation offered by the original models.

These concerns center around the presence of other stable behaviors called a pooling equilibria. If we suppose that costs and benefits are arranged so as to make signaling stable, there is another outcome which would also be stable. Suppose that the parent always transfered the resource regardless of signal sent by the child. In such a case, the child would never want to beg, since he is inuring a cost for no benefit. If the child is needy sufficiently often, this situation remains an equilibrium (Bergstrom and Lachmann, 1997). If the child is infrequently needy, then there is a similar equilibrium where the child never signals and the parent never transfers the resource.

In situations like this, where more than one state is stable, one must determine which is more likely to evolve. Bergstrom and Lachmann (1997) and RodríguezGironés et al (1996) observed that in some cases, both the parent and the child would prefer a pooling equilibrium to a signaling equilibrium. This occurs because the magnitude of the cost is so high as to outweigh the loss to the parent from occasionally transferring the resource to the healthy child. Given that we presume the ancestral states of most organisms do not involve signaling, this introduces a difficult evolutionary mystery - why should evolution have moved a population from a stable superior state to an inferior one so often?

This concern was further emphasized by an explicit model of the evolutionary process (Huttegger and Zollman, 2010). Huttegger and Zollman found that in many cases of interest, it is relatively unlikely for a random population to evolve to state where signaling is present. That these possibilities were ignored is a result of the methodology that focuses on stability rather than dynamical concerns (Huttegger and Zollman, 2012).

\section{Alternatives to Handicaps}

These concerns, along with the general theoretical interest of having all the possibilities appropriately demarcated, has led several theorists to posit alternative theories which might explain the evolution and stability of signaling systems without relying on large costs of signals.

\begin{tabular}{cccc}
\multirow{2}{*}{ Parent state } & \multicolumn{3}{c}{ Child state } \\
& Desperate & Needy & Healthy \\
\hline \multirow{2}{*}{ Needy } & $\mathrm{P}:+$ & $P:-$ & $\mathrm{P}:-$ \\
& $\mathrm{C}:+$ & $C:+$ & $\mathrm{C}:-$ \\
\hline \multirow{2}{*}{ Healthy } & $\mathrm{P}:+$ & $\mathrm{P}:+$ & $P:-$ \\
& $\mathrm{C}:+$ & $\mathrm{C}:+$ & $C:+$
\end{tabular}

Table 1 Conflict of interest for Lachmann and Bergstrom's Sir Philip Sidney game. "P" indicates parent and "C" indicates child. A plus indicates that a transfer would be fitness enhancing for that individual. Cases of conflict of interest are marked in italics.

\subsection{Penalties for dishonesty}

A number of scholars have noted that in these models the critical cost is not the cost paid by those who signal honestly, but by those who signal dishonestly (Hurd, 1995; Lachmann et al, 2001; Számadó, 1999). It is entirely plausible that there many be no observed signal costs in equilibrium, so long as there would be costs should the system stray from equilibrium.

For instance, in the simple model with which we began, it is possible that in equilibrium that the needy individual pays no cost for begging, so long as there is a significant cost for the healthy individual to beg. If this cost for dishonest begging is sufficiently high, then the healthy individual will be unwilling to pay the cost in order to secure the resource. In this situation there would be no observed signal costs because the health individual would never beg.

While mathematically cogent, there has not yet been a reasonable mechanism suggested for this type of enforcement costs in the case of parent-offspring interaction. Punishment for lying by conspecific has been identified as one potential mechanism for maintaining honesty for signals that indicate social status (Møller, 1987; Molles and Vehrencamp, 2001; Rohwer, 1977).

\subsection{Partial Pooling}

In the traditional model, due to Maynard Smith (1991), there are only two states of need. This is, of course, an idealization used for illustrative purposes. Unfortunately, this idealization obscures an important possible alternative to handicap theory. Lachmann and Bergstrom (1998) demonstrate that when we expand the possible states of need to include some notion of degree, there are additional equilibria called partial pooling equilibria.

In these equilibrium different types "pool" together by using the same signal. As an illustrative example they consider a situation where there are three states of need for the child, desperate, needy, and healthy, and two states for the parent needy and healthy. As 
in the simpler game there is a partial conflict of interest illustrated in Table 1. The conflict of interest exists when the parent and the child are both either needy or healthy. Like the simpler version of this game, there are signaling equilibria where there are three signals, two of which come with a cost, where the child honestly reveals his state of need to the parent.

Lachmann and Bergstrom show that for some probability distributions over the parent and child state, there exist equilibria where the desperate and needy child both send the same signal or where the needy and healthy child both send the same signal. In these equilibria signal cost can be lower than in the signaling equilibrium.

In a later paper, Bergstrom and Bergstrom (1999) show that (in an even richer model) there can be equilibria where all signals are free but there is nonetheless some honest communication. These equilibria can be better for both the parent and child than the traditional signaling equilibrium.

These equilibria, like the hybrid equilibria discussed in the next section, are interesting because they involve some information transfer, but less than the traditional signaling equilibrium. In the partial pooling equilibria the parent is sometimes "tricked" into providing the resource when she would otherwise prefer not to transfer. The cost of transferring in these cases is offset by the gain to the child from paying a lower cost to signal (since the parent and the child are presumed to be related, this also represents a gain to the inclusive fitness of the parent).

\subsection{Hybrid equilibria}

The partial pooling equilibria of the last section involve two types pooling together by using the same signal and thus becoming indistinguishable for the receiver. Another method by which types might pool is by adopting probabilistic strategies, where one type sometimes pools with another and sometimes does not. This type of equilibrium is called a "hybrid" equilibrium.

In the hybrid equilibrium the needy child always sends a cheap-but-not-free signal and the healthy child occasionally sends that signal. The parent, upon receiving the cheap-but-not-free signal occasionally transfers the resource, but not always. The frequency which with the healthy child signals and the parent transfers depends on the relative value of the resource and the frequency with which the child is needy (Huttegger and Zollman, 2010; Zollman et al, 2012).

These equilibria are not stable in the same way that the traditional signaling equilibria are stable. In one model of evolution, called the two-population replicator dynamics (Taylor and Jonker, 1978; Hofbauer and Sigmund, 1998), populations approach this equilibrium, but then cycle around it indefinitely (Huttegger and Zollman, 2010; Zollman et al, 2012). Further research is necessary to determine how robust this result is to modification of the underlying evolutionary dynamics.

When the hybrid equilibrium exists, there still remain the total pooling equilibria. Huttegger and Zollman (2010) show that the hybrid equilibrium seems more likely to evolve than the signaling equilibrium in analogous situations. Ongoing research is attempting to determine which equilibrium is most likely in situations where one might evolve to pooling, hybrid, or the traditional signaling equilibria.

\subsection{Reputation}

One neglected feature of parent-offspring interactions is that they take place repeatedly. The possibility of this as a solution to parent-offspring communication was suggested but not demonstrated conclusively by Searcy and Nowicki (2005).

If the parent could observe the state of the child after transferring or withholding the resource, then it could punish dishonesty directly by refusing to respond to begging again. This seems an unlikely possibility, so the situation is made rather more complicated.

There remains a possibility for detecting cheating, if the parent "knows" the expected frequency with which the child will be needy, she can observe how often the child signals. If the child signals far too often, the parent can refuse to allocate the resource at all. This threat of retaliation will prevent the child from signaling more frequently than will be tolerated by the parent.

The mathematical coherence of this possibility has been recently illustrated by Rich and Zollman (2012). In these equilibria the parent "punishes" too-frequent signaling by the child, and thus prevents the child from deceiving the parent, even if all signals are free. In this model, however, there are a huge multiplicity of equilibria where the parent tolerates different frequencies of signaling by the child. Further research is needed to determine the evolutionary plausibility of these different equilibria.

A similar result was shown in (Silk et al, 2000) as it pertains to signaling between potential rivals. They show that cost-free signaling can be stable in repeated interactions where the underlying state (in this case intentions toward a rival) can be observed after the interaction, and thus veracity can be determined afterthe-fact. 


\subsection{Correlated interaction}

Suppose for the moment that a parent and child are out of equilibrium. The child honestly signals his parent, despite signal cost being too low to sustain this situation. Consider for a moment the behavior of the healthy child. The healthy child is failing to send a signal that, if sent, would improve the child's fitness at the expense of the parent. In this part of the overall interaction we have a case of altruism, and as a result many of the explanations for biological altruism can be brought to bear here.

The most popular solution to the biological altruism problem, inclusive fitness theory, cannot help in this context, since parent-offspring conflicts arise despite the high relatedness between parents and offspring. Instead, we must turn to other solutions to altruism.

Although there are a large number of potential solutions to the problem of altruism, Skyrms (1994) (following Hamilton $(1964 \mathrm{a}, \mathrm{b})$ ) has argued that they all share a common core of introducing correlation between types. If altruistic types can be made (one way or another) to interact more often than would be expected in a randomly mixing population, altruism could evolve.

Little has been done to connect this literature to the problem of communication between parents and offspring or between potential mates. Relatedness might, beyond inclusive fitness, introduce additional correlation - lying children will half the time, when they become adults, have lying children as well - which may introduce an additional long-term cost to lying which would not show up in experiments designed to measure the short-terms costs.

\subsection{Non-uniform error}

In Zahavi's treatment of the Handicap Principle (especially Zahavi and Zahavi 1997), he occasionally vacillates between describing Handicap signals - those phenotypes that could be exhibited by different types - and signs - those phenotypes that could not be exhibited by certain types. If the parent could directly observe the state of need of the child, or some very close correlate, then this would function as a sign - an unfakable signal.

If there is a natural constraint that prevents the evolution of deceptive behavior, then the use of that sign presents no evolutionary mystery. As Maynard Smith and Harper (2003) point out, the border between signs and signals can be a very blurry one. For instance, if the parent begins by observing abdomen distention to determine the state of need of its child, there might now be evolutionary pressure to allow children to independently control abdomen distention. If this ability evolves, distention now moves from becoming a sign to becoming a signal.

One possibility currently under investigation by Huttegger et al (2012) is that certain signals can be faked but only with some error. It might be that, while both the needy and healthy child can beg, there is a higher probability that the needy child will beg in a believable way. In such a case, the parent might do best by responding to "believable" begging by transferring the resource - even if this means occasionally giving the resource to the healthy child. As in the hybrid equilibrium discussed above, these situations involve imperfect information transmission, but can occur with low signal costs.

This explanation lies at the border of signals and signs since the signal can only be imperfectly faked. As a result, this offers an explanation for honest signaling only by moving the questions slightly in the direction of non-signaling behavior.

\subsection{Non-signaling alternatives}

If we move even one step further away from signaling, and consider other potential explanations for "signalinglike" behavior, we find many. The most common, and often tested, alternative explanation is that the apparent signal is a non-adaptive byproduct of the underlying trait which is observed directly (or observed by a correlated sign). For example, a parent might be able to directly observe the state of need of the child, either by observing some correlate to health or by remembering the amount of food previously provided to the child. Especially in the cases of begging in birds, this alternative has been extensively tested and rejected in many cases. However, it remains an important alternative explanation that must be dismissed.

When we move from parent-child communication to communication between potential mates, the number of non-signaling alternative theories abound. Sexual selection is perhaps the oldest and most well known, where a run-away process produces ever more extreme ornamentation in one sex and more extreme preference for the ornamentation in the other (Fisher, 1930).

Another alternative, called the sensory exploitation hypothesis, is perhaps the most difficult to distinguish empirically (Dawkins and Guilford, 1996; Endler, 1993; Ryan and Rand, 1993). Under this hypothesis one sex manipulates a pre-existing preference in the other in order to encourage non-adaptive preference in the other sex. For instance, if a particular female fish has a preference for red things which has evolved in order to improve foraging, a red colored male might be preferred 
by that female as well. In such a case, red colored males will have a selective advantage. The female preference might be sustained by its contribution to effective foraging even if it is maladaptive for mate choice.

\section{Conclusion}

Much of the theoretical work of the past several decades has focused on demonstrating the theoretical coherence of the Handicap Principle in a number of different types of interactions. As a result, the theory has come to occupy a central place in biological theory despite both empirical and theoretical concerns. This paper attempts to remedy this by introducing a number of, admittedly less developed, alternative theories which might account for the evolution and stability of signaling (or signaling-like) behaviors. With additional theoretical and empirical work, it is hoped that these alternative theories might be better understood and perhaps employed to explain cases of signaling found in the wild.

\section{References}

Bachmann G, Champbell M (1998) The Energetic Cost of Begging Behavior in Nestling House Wrens. Animal Behavior 55:1607-1618

Bergstrom CT, Bergstrom T (1999) Does Mother Nature punish rotten kids? Journal of Bioeconomics 1:47-72

Bergstrom CT, Lachmann M (1997) Signalling among relatives. I. Is costly signalling too costly? Philosophical Transactions of the royal Society of London B 352:609-617

Bergstrom CT, Lachmann M (1998) Signaling among relatives. III. Talk is Cheap. Proceedings of the National Academy of Sciences of the USA 95:5100-5105

Borgia G (1993) The Cost of Display in the NonResource-Based Mating System of the Satin Bowerbird. American Naturalist 141(5):729-743

Brilot BO, Johnstone RA (2003) The limits to costfree signalling of need between relatives. Proceedings of the Royal Society of London B 270:1055-1060

Caro TM, Lombardo L, Goldizen AW, Kelly M (1995) Tail-flagging and other antipredator signals in whitetailed deer: new data and synthesis. Behavioral Ecology 6(4):442-450, DOI 10.1093/beheco

Chappell M, Zuk M, Kwan T, Johnsen T (1995) Energy cost of an avian vocal display: crowing in red junglefowl. Animal Behaviour 49(1):254-256

Davis J, O'donald P (1976) Sexual selection for a handicap: a critical analysis of Zahavi's model. Journal of Theoretical Biology 57(2):345-354
Dawkins MS, Guilford T (1996) Sensory bias and the adaptiveness of female choice. The American Naturalist 148(5):937-942

Endler JA (1993) Some general comments on the evolution and design of animal communication systems. Philosophical Transactions of the royal Society of London B 340:215-255

Fisher RA (1930) The Genetical Theory of Natural Selection. Oxford University Press, Oxford

Godfray HCJ, Johnstone RA (2000) Begging and bleating: the evolution of parent-offspring signalling. Philosophical Transactions of the Royal Society of London Series B: Biological Sciences 355(1403):15811591, DOI 10.1098/rstb.2000.0719

Grafen A (1990) Biological Signals as Handicaps. Journal of Theoretical Biology 144:517-546

Grose J (2011) Modelling and the fall and rise of the handicap principle. Biology and Philosophy 26(5):120

Hamilton W (1964a) The genetical evolution of social behaviour. I. Journal of Theoretical Biology 7(1):116, DOI 10.1016/0022-5193(64)90038-4

Hamilton W (1964b) The genetical evolution of social behaviour. II. Journal of Theoretical Biology 7(1):1752, DOI 10.1016/0022-5193(64)90039-6

Haskell D (1994) Experimental evidence that nestling begging behaviour incurs a cost due to nest predation. Proceedings of the Royal Society of London B 257:161-164

Hofbauer J, Huttegger S (2008) Feasibility of communication in binary signaling games. Journal of Theoretical Biology 254(4):843-849

Hofbauer J, Sigmund K (1998) Evolutionary Games and Population Dynamics. Cambridge University Press, Cambridge

Hurd PL (1995) Communication in Discrete ActionResponse Games. Journal of Theoretical Biology 174:217-222

Huttegger S (2007) Evolution and Explanation of Meaning. Philosophy of Science 74(1):1-27

Huttegger S, Zollman KJ (2009) Signaling Games: The Dynamics of Evolution and Learning. In: Benz A (ed) Language, Games, and Evolution

Huttegger S, Zollman KJ (2010) Dynamic stability and basins of attraction in the Sir Philip Sidney game. Proceedings of the Royal Society of London B 277:1915-1922

Huttegger S, Skyrms B, Smead R, Zollman K (2010) Evolutionary Dynamics of Lewis Signaling Games: Signaling Systems vs. Partial Pooling. Synthese 172(1):177-191

Huttegger S, Skyrms B, Zollman K (2012) Probe and Adjust in Information Transfer Games. Erkenntnis 
forthcoming

Huttegger SM, Zollman KJ (2012) Methodology in Biological Game Theory. British Journal for the Philosophy of Science forthcoming

Johnstone R, Grafen A (1992) The continuous Sir Philip Sidney Game: A simple model of biological signaling. Journal of Theoretical Biology 156:215-236

Johnstone RA, Grafen A (1993) Dishonesty and the handicap principle. Animal Behaviour 46(4):759-764, DOI 10.1006/anbe.1993.1253

Kirkpatrick M (1986) The handicap mechanism of sexual selection does not work. American Naturalist pp 222-240

Lachmann M, Bergstrom CT (1998) Signalling among relatives. II. Beyond the Tower of Babel. Theoretical Population Biology 54:146-160

Lachmann M, SzaḿadoŚ, Bergstrom CT (2001) Cost and conflict in animal signals and human language. Proceedings of the National Academy of Sciences 98(23):13,189-13,194

Leech S, Leonard M (1997) Begging and the risk of predation in nestling birds. Behavioral Ecology 8(6):644-646

Maynard Smith J (1991) Honest Signaling, The Philip Sidney Game. Animal Behavior 42:1034-1035

Maynard Smith J, Harper D (2003) Animal signals. Oxford University Press, Oxford

McCarty J (1996) The energetic cost of begging in nestling passerines. The Auk 113(1):178-188

Møller AP (1987) Social control of deception among status signalling house sparrows: Passer domesticus. Behavioral Ecology and Sociobiology 20:307-311

Molles LE, Vehrencamp SL (2001) Songbird cheaters pay a retaliation cost: evidence for auditory conventional signals. Proceedings of the Royal Society of London B 268:2013-2019

Pawlowitsch C (2008) Why evolution does not always lead to an optimal signaling system. Games and Economic Behavior 63:203-226

Pomiankowski A, Iwasa Y (1998) Handicap Signaling: Loud and True? Evolution 52(3):928-932

Rich P, Zollman KJ (2012) Reputation-Based Signaling Equilibria in the Sir Philip Sidney Game. Manuscript

Rodríguez-Gironés M, Cotton P, Kacelnik A (1996) The evolution of begging: signaling and sibling competition. Proceedings of the National Academy of Sciences 93(25):14,637

Rohwer S (1977) Status Signaling in Harris Sparrows: Some Experiments in Deception. Behaviour 61(1/2):107-129

Ryan MJ, Rand AS (1993) Sexual selection and signal evolution: The ghost of biases past. Philosophical Transactions of the royal Society of London B
340(1292):187-195

Searcy WA, Nowicki S (2005) The Evolution of Animal Communication. Princeton University Press, Princeton

Silk JB, Kaldor E, Boyd R (2000) Cheap talk when interests conflict. Animal Behaviour 59(2):423-432, DOI 10.1006/anbe.1999.1312

Skyrms B (1994) Darwin Meets the Logic of Decision: Correlation in Evolutionary Game Theory. Philosophy of Science 61(4):pp. 503-528

Smith J (1976) Sexual selection and the handicap principle. Journal of Theoretical Biology 57(1):239-242

Számadó S (1999) The validity of the handicap principle in discrete action-response games. Journal of theoretical biology 198(4):593-602

Taylor P, Jonker L (1978) Evolutionarily Stable Strategies and Game Dynamics. Mathematical Biosciences 40:145-156

Trivers RL (1974) Parent-Offspring Confict. American Zoologist 14(1):249-264

Zahavi A (1975) Mate Selection - A Selection for a Handicap. Journal of Theoretical Biology 53:205-214

Zahavi A, Zahavi A (1997) The Handicap Principle: A Missing Piece of Darwin's Puzzle. Oxford University Press, New York

Zollman KJ, Bergstrom CT, Huttegger SM (2012) Cheaper-than-costly signaling. Proceedings of the Royal Society of London B forthcoming 